\title{
Economic Priorities for Reforesting Unstocked Forest Land in British Columbia
}

\author{
by \\ Peter H. Pearse, Andrea J. Lang and Kevin L. Todd'
}

\begin{abstract}
The cost of rehabilitating the accumulated backlog of unsatisfactorily stocked forest lands in British Columbia is calculated for each site class and type in each region. These estimates suggest that, at 1983 silvicultural costs, it would require almost $\$ 1.3$ billion to reforest all the existing backlog, or $\$ 570$ million to reforest only the good and medium sites.
\end{abstract}

These cost estimates, supplemented with data relating to forest growth on various land categories, enable calculation of the cost of producing timber by rehabilitating unreforested land. This reveals a very wide range of costs, depending on site quality and region. It provides a framework for establishing economic priorities for silvicultural effort.

The analysis demonstrates that the benefits generated with the limited budget available for forest rehabilitation can be substantially enhanced if funds are allocated according to economic priorities rather than by non-economic criteria.

\section{Résumé}

Les coûts de la réhabilitation de l'accumulation de terrains non régénérés de façon satisfaisante en Colombie Britannique sont calculés par classe de site et selon son type dans chaque région. Ces estimés suggèrent en référence aux coûts de traitements sylvicoles de 1983 , qu'il en coûterait près de $\$ 1.3$ milliard pour régénérer toute l'accumulation, ou encore $\$ 570$ millions pour régénérer seulement les sites de bonne et moyenne qualité.

Ces prévisions de coûts, en plus des données relatives à la croissance forestière sur diverses catégories de terrains, permettent de calculer les coûts de production de la matière ligneuse suite à la réhabilitation des terrains non régénérés. Ceci suggère une large gamme de coûts, selon la qualité du site et la région. Ceci procure un cadre permettant d'établir les priorités économiques de l'effort sylvicole.

L'analyse démontre que les bénéfices générés selon le budget limité disponible pour la réhabilitation forestière peuvent être subtantiellement accrus si les fonds sont alloués selon une priorité économique plutôt que selon des critères non économiques.

\section{Introduction}

British Columbia's large forest industry has historically enjoyed the advantage of exceptionally high-quality softwood timber. The end of the original stock of virgin timber is now in sight. It will last for a few more years in the more heavily exploited regions, and a few more decades elsewhere. The industry then will be forced to adjust to second-growth timber and probably lower cutting rates. These adjustments will be difficult and are raising anxieties within both the forest industry and governments.

Dr. Pearse is a Professor of Forestry at the University of British Columbia and Project Leader of the Forest Economics and Policy Analysis Project. Andrea Lang is a research assistant with the Project. Kevin Todd was formerly a Research Assistant with the Faculty of Forestry at the University of British Columbia. The research for this paper was sponsored by the Forest Economics and Policy Analysis Project, which is supported by a grant from the Canadian Forestry Service. The analysis and conclusions should not be attributed to the sponsors however.

The authors are indebted to the Ministry of Forests for some of the data used in this study. We are also grateful for the helpful comments we received on an early this study. We are also grateful for the helpful comments we received on an early
draft of this paper from a number of experts, especially Ray Addison of British Columbia's Ministry of Forests, Alex Fraser of the Canadian Forestry Service and Trevor Jeanes of Balco Forest Industries.

The authors, alone, are responsible for any errors or misrepresentations that remain.
These concerns have focused attention on the future supply of timber and the adequacy of reforestation programs. In an earlier paper we examined the current reforestation effort in British Columbia (Pearse, Lang and Todd, 1986). Among other things, we assessed the extent of the accumulated backlog of unreforested land, which is a particular concern among foresters because of the continuing loss of potential growth on these extensive areas. ${ }^{2}$ Rehabilitation of these unstocked lands is widely advocated, and a start is planned under a forest renewal program jointly funded by the federal and provincial governments (CanadaBritish Columbia 1985). But the magnitude of the problem presents an enormous undertaking, with costs in the hundreds of millions of dollars. This paper examines the economic dimensions of this issue and suggests some policy priorities.

The paper begins, in the following section, with a summary of the extent of unstocked forest land in British Columbia. We then present estimates of the costs that would be incurred in rehabilitating them, according to their location

2For expressions of this concern, see Canadian Institute of Forestry 1983 Environment Canada 1984; and M.F. Painter and Associates Ltd. 1984. 
and condition. This, with information about expected growth rates on each land category, enables us to demonstrate economic priorities for the rehabilitation effort in terms of costeffectiveness. In the concluding section we summarize the implications of these findings for silvicultural policy in British Columbia

\section{The Backlog of Unstocked Forest Lands}

Because the reforestation issue has been confused by inconsistent terminology, some definitions are necessary at the outset. Here, we use the term "not satisfactorily restocked", or NSR in the Ministry of Forests' abbreviation, to refer to all potentially productive forest land that is not stocked to the Ministry's minimum acceptable standard.

There are several sub-categories of these lands. Some have been denuded only recently; those for which the prescribed regeneration period has not yet elapsed are referred to as "current NSR", while those for which the regeneration period has elapsed are "backlog NSR". Some of the current NSR lands are so classified because they have been at least partially denuded and their restocking is uncertain; this "disturbed, stocking doubtful" (DSD) category is only a temporary classification, pending confirmation through field information. Some of the backlog NSR lands are overgrown with brush and weed species, and these are subclassified as "non-commercial brush" (NCBr) lands. Finally, unstocked lands can be classified among four grades of site quality, or potential productivity, which has an important bearing on their priority for rehabilitation. "Rehabilitation", as it is used in this paper, includes site preparation where this is necessary, as well as planting with commercial species.

Table 1 summarizes our best estimates of the unstocked forest lands in British Columbia by region and category. The figures in this table are substantially smaller than the area classified as NSR in the Ministry's inventory and forest history records. This is because the original data have been reduced by a fraction that reflects the Ministry's expectation about the proportion of land in this category that is actually satisfactorily stocked. In effect, much of the land classified as NSR is found, upon field inspection, to be adequately stocked. The results of past regeneration surveys in areas recorded as NSR have been used to calculate how much the gross figures should be reduced to indicate the unstocked area more realistically. We refer to these adjustments as "adjustment factors" (rather than the Ministry's "regeneration factors" which inappropriately suggests a rate of regeneration rather than the portion assumed to be, or become regenerated).

Table 1 indicates that there are an estimated 1635 thousand hectares of all categories of potentially productive but unstocked forest lands in the province. Of this, 333 thousand hectares are current NSR, which is of only passing interest here because it is a normal transitional category and is not evidence of either deficient reforestation effort or rehabilitation problem. The focus of interest in this paper is the 1302 thousand hectares of backlog NSR, which include both the NCBr and other backlog NSR categories.

A large proportion of the backlog, some 73 percent, is in the vast Prince George Forest Region of British Columbia's northern interior. Much of this is the result of uncontrolled forest fires in the remote parts of this region in past decades. This also explains some of the backlog NSR area in the Prince Rupert Forest Region, which includes remote northern interior forest as well. Significantly, 60 percent of the backlog NSR Land in these northern areas is of poor and low sites. In the other regions only about a third of the area in this category is of poor and low site quality.

The backlog of NSR lands is constantly changing, as some areas reforest naturally and new areas are added. It is likely that new additions have been declining in recent years as a result of expanded reforestation programs. The Ministry's planned further expansion of reforestation appears sufficient to eliminate further net growth in the NSR backlog within the next couple of years (Pearse, Lang and Todd, 1986).

Table 1. Inadequately stocked Crown land at the beginning of $1984^{\mathrm{a}}$.

\begin{tabular}{|c|c|c|c|c|c|c|c|}
\hline & & & & rest Regi & & & \\
\hline & Cariboo & Kamloops & $\frac{\text { Nelson }}{1}$ & $\begin{array}{l}\text { Prince } \\
\text { George } \\
\text { sand Hec }\end{array}$ & $\begin{array}{l}\text { Prince } \\
\text { Rupert }\end{array}$ & $\underline{\text { Vancouver }}$ & Province \\
\hline $\begin{array}{l}\text { Current NSR: } \\
\text { Good \& medium sites } \\
\text { Poor \& low sites }\end{array}$ & $\begin{array}{l}21.1 \\
12.4 \\
33.5\end{array}$ & $\begin{array}{r}26.2 \\
\frac{6.6}{32.8}\end{array}$ & $\begin{array}{l}22.8 \\
11.3 \\
34.1\end{array}$ & $\begin{array}{l}57.3 \\
\frac{75.2}{132.4}\end{array}$ & $\begin{array}{l}14.6 \\
76.2 \\
90.8\end{array}$ & $\begin{array}{l}7.9 \\
1.7 \\
9.6\end{array}$ & $\begin{array}{c}149.9 \\
183.3 \\
333.2\end{array}$ \\
\hline $\begin{array}{l}\text { Backlog NSR: } \\
\text { a) NCBr: } \\
\text { Good \& medium sites } \\
\text { Poor \& low sites }\end{array}$ & $\begin{array}{l}1.4 \\
3.2 \\
4.5\end{array}$ & $\begin{array}{l}4.3 \\
2.4 \\
6.6\end{array}$ & $\begin{array}{l}31.8 \\
19.2 \\
51.0\end{array}$ & $\begin{array}{l}348.4^{\mathrm{b}} \\
410.4 \\
758.8\end{array}$ & $\begin{array}{r}13.2 \\
38.3 \\
51.4\end{array}$ & $\begin{array}{l}1.8 \\
0.6 \\
2.4\end{array}$ & $\begin{array}{l}400.7 \\
474.1 \\
874.8\end{array}$ \\
\hline $\begin{array}{l}\text { b) Other backlog NSR: } \\
\text { Good \& medium sites } \\
\text { Poor \& low sites }\end{array}$ & $\begin{array}{r}20.9 \\
9.5 \\
30.3\end{array}$ & $\begin{array}{l}21.0 \\
10.0 \\
31.0\end{array}$ & $\begin{array}{l}39.2 \\
21.6 \\
60.8\end{array}$ & $\begin{array}{r}83.0 \\
110.6 \\
193.6\end{array}$ & $\begin{array}{l}12.7 \\
81.3 \\
94.0\end{array}$ & $\begin{array}{r}10.8 \\
6.4 \\
17.2\end{array}$ & $\begin{array}{l}187.5 \\
239.4 \\
426.8\end{array}$ \\
\hline $\begin{array}{l}\text { c) Total Backlog NSR: } \\
\text { (current and backlog) }\end{array}$ & $\frac{34.5}{68.3}$ & $\frac{37.6}{70.3}$ & $\frac{111.8}{145.8}$ & $\frac{952.4}{1084.8}$ & $\frac{145.5}{236.3}$ & $\frac{19.6}{29.2}$ & $\frac{1301.6}{1634.8}$ \\
\hline
\end{tabular}

${ }^{3}$ including private lands within Tree Farm Licenses but excluding all other private lands. The gross areas of NSR land have been reduced by correction factors to allow for the proportion of lands in this category that is likely to be adequately reforested (see text).

${ }^{b}$ This includes the lands in the Feace and Fort Nelson districts reclassified by the ministry from poor 10 good and medium site classes between its 1979 and 1984 Forest and Range Resource Analyses.

Source: Ministry of Forests, unpublished data 


\section{Costs of Rehabilitating Backlog NSR Land}

Discussions about rehabilitating the backlog of NSR lands have not, so far, been supported with much analysis of the costs and benefits of doing so. The remainder of this paper attempts to throw light on these economic considerations.

The cost of rehabilitating backlog NSR lands can be calculated by identifying the silvicultural treatments required for each NSR category, and adding together the costs of these treatments. Costs per hectare of site preparation and planting are published by the Ministry of Forests for each forest region (Ministry of Forests 1985). To allow for unsuccessful reforestation or plantation failure we have added a further eight percent to the cost, based on the Ministry's estimates (Ministry of Forests 1984b). Further details about the costs are contained in Appendix A.

The results are reproduced in Table 2. The cost of rehabilitating lands classified as $\mathrm{NCBr}$ is generally higher than for other NSR lands because the former normally requires brush clearing before it can be planted. The total cost per hectare ranges between $\$ 738$ to $\$ 1636$, with both extremes occurring in the Vancouver Forest Region.

In Table 2, these costs are multiplied by the total number of hectares in each category in each of the forest regions, to reveal the total cost of rehabilitating all the backlog NSR lands listed in Table 1. The results suggest that, at 1983 silvicultural costs, it would cost $\$ 1260$ million to rehabilitate all of the backlog NSR land in the province.
The Ministry considers that only a fraction of these backlog NSR lands deserves attention, however. All "poor" and "low" sites are excluded as being insufficiently productive to justify the rehabilitation effort and expenditure (Ministry of Forests, 1984a). This eliminates a considerable proportion of the backlog, ranging from 32 percent in the Kamloops Forest Region to 82 percent in the Prince Rupert region. Altogether, 715 thousand hectares are thus excluded; the remaining "good" and "medium" sites in the backlog NSR (as shown in Table 1) amount to 588 thousand hectares. We refer to this reduced area as "non-stocked priority backlog" (NPB) lands.

Using the costs per hectare in Table 2, we have calculated the total cost of rehabilitating only the NPB lands; that is, the good and medium sites. The results, shown in Table 3 , suggest that at 1983 silvicultural costs it would require $\$ 570$ million to rehabilitate all of these lands.

\section{Priorities for the Rehabilitation Effort}

Because the funds available for rehabilitating the backlog NSR lands fall far short of the amount needed to restock all of these areas, it is necessary to identify those that deserve highest priority to ensure maximum returns from limited budgets. The present federal-provincial agreement that provides funds for this purpose specifies that factors such as location, site class, costs, and local timber supplies will be considered in selecting projects; but it does not suggest how these considerations are to be accounted for and weighed in order to establish priorities. Nor does the Ministry have any explicit criterion for identifying lands that warrant rehabilitation, beyond excluding lands of poor and low site quality.

Table 2. Estimates of the costs of rehabilitating all backlog NSR lands in British Columbia.

\begin{tabular}{|c|c|c|c|c|c|c|c|}
\hline \multirow[b]{2}{*}{ Forest Region } & \multicolumn{3}{|c|}{$\mathrm{NCBr}$} & \multicolumn{3}{|c|}{ Other backlog NSR } & \multirow{2}{*}{$\begin{array}{c}\text { All Backlog } \\
\text { NSR }\end{array}$} \\
\hline & Area & $\begin{array}{c}\text { Treatment } \\
\text { cost }\end{array}$ & $\begin{array}{l}\text { Total } \\
\text { cost }\end{array}$ & Area & $\begin{array}{c}\text { Treatment } \\
\text { cost }\end{array}$ & $\begin{array}{l}\text { Total } \\
\text { cost }\end{array}$ & \\
\hline & (thousand ha) & (\$/ha) & (million \$) & (thousand ha) & (\$/ha) & (million \$) & (million \$) \\
\hline Cariboo & 4.5 & 941 & 4.3 & 30.3 & 916 & 27.8 & 32.1 \\
\hline Kamloops & 6.6 & 771 & 5.1 & 31.0 & 918 & 28.4 & 33.5 \\
\hline Nelson & 51.0 & 908 & 46.3 & 60.8 & 869 & 52.8 & 99.1 \\
\hline Prince George & 758.8 & 1034 & 784.3 & 193.6 & 831 & 160.8 & 945.0 \\
\hline Prince Rupert & 51.4 & 1039 & 53.4 & 94.0 & 858 & 80.6 & 134.0 \\
\hline Vancouver & 2.4 & 1636 & 3.9 & 17.2 & $\underline{738}$ & 12.7 & 16.6 \\
\hline all regions & 874.8 & 1 055(avg) & 897.3 & 426.8 & 855(avg) & 363.1 & 1260.4 \\
\hline
\end{tabular}

"Based on 1983 costs. See Appendix A for details.

Table 3. Estimates of the costs of rehabilitating non-stocked priority backlog (NPB) lands (i.e. backlog NSR lands of good and medium sites).

\begin{tabular}{|c|c|c|c|c|c|c|c|}
\hline \multirow[b]{2}{*}{ Forest Region } & \multicolumn{3}{|c|}{$\mathrm{NCBr}$} & \multicolumn{3}{|c|}{ Other backlog NSR } & \multirow{2}{*}{$\begin{array}{c}\begin{array}{c}\text { All priority } \\
\text { backlog } \\
\text { (NPB) }\end{array} \\
\text { Total cost }\end{array}$} \\
\hline & Area & $\begin{array}{c}\text { Treatment }{ }^{\mathrm{a}} \\
\text { cost }\end{array}$ & $\begin{array}{l}\text { Total } \\
\text { cost }\end{array}$ & Area & $\begin{array}{c}\text { Treatment } \\
\text { cost }\end{array}$ & $\begin{array}{l}\text { Total } \\
\text { cost }\end{array}$ & \\
\hline & (thousand ha) & (\$/ha) & (million \$) & $\overline{\text { (thousand ha) }}$ & (\$/ha) & (million \$) & (million \$) \\
\hline Cariboo & 1.4 & 941 & 1.3 & 20.9 & 916 & 19.1 & 20.4 \\
\hline Prince George & 348.4 & 1034 & 360.1 & 83.0 & 831 & 68.9 & 429.1 \\
\hline Prince Rupert & 13.2 & 1039 & 13.7 & 12.7 & 858 & 10.8 & 24.6 \\
\hline Vancouver & 1.8 & 1636 & 2.9 & 10.8 & 738 & 8.0 & 10.8 \\
\hline all regions & 400.7 & 1 055(avg) & 410.1 & 187.5 & 855(avg) & 160.2 & 570.3 \\
\hline
\end{tabular}

"Based on 1983 costs. See Appendix A for details. 
The absence of clear criteria for ranking priorities for silvicultural treatment is a serious deficiency of the present policy framework because, as we show below, the costeffectiveness of expenditures on different categories of land varies widely. This is not to suggest that economic returns should be the only guide in selecting priorities. But the ultimate purpose of the reforestation program is clearly to provide for future commercial timber supplies, and this implies that investments in this type of silviculture should be guided largely by economic criteria.

Ideally, the cost of rehabilitating each site should be compared with the increased present worth of the crop that could ultimately be harvested. Those sites that show the greatest benefits in relation to costs would be those deserving highest priority for rehabilitation. However, this would require speculation about the value of timber several decades hence and the variation in timber values among locations and sites, which goes beyond the scope of this paper.

However, we can provide a starting point for establishing priorities for the rehabilitation effort by demonstrating the cost per cubic metre of producing timber by rehabilitating backlog NSR lands in the various regions and categories. These costs indicate the net value that the timber must have when it reaches harvesting age to cover the cost of rehabilitation in each case. The sites can then be ranked from lowest to highest cost-effectiveness in terms of producing timber. Other things being equal (a presumption which we qualify below), the ranking indicates where investments should be made to yield the highest economic return from rehabilitation.

To make these estimates, we have adopted certain simplifying assumptions. First, we have assumed that the only costs involved are those of rehabilitating and reforesting the land (see Appendix A). This implies no additional stand tending or protection costs (or, at least, none in excess of those that would be incurred if the sites were left to recover naturally). Second, we assume that our allowance of an additional eight percent of costs for plantation failure is sufficient to cover all the costs incurred in achieving successful rehabilitation. Third, we assume that the volume of timber that will be produced is accurately indicated in the Ministry's estimates of yields per hectare for managed stands, by species, site and region, without any deductions for decay, waste or breakage. (Since managed stand yield tables are not available for low site classes, these sites were excluded from the analysis.) Fourth, we have assumed that the stands will be harvested at the age at which their mean annual increment of growth is maximized, which is the Ministry's general criterion for selecting the crop rotation period. The age at harvest ranges from 60 years on good sites in the Vancouver region to 160 years on poor sites in the northern interior (see Appendix B). Finally, we have adopted a real rate of interest of three percent in calculating the cumulated cost of the initial silvicultural investment over the rotation period.

The results are summarized in Table 4, which for each case shows the cost of the stand per cubic metre, cumulated at three percent to the assumed harvest age. ${ }^{3}$

\footnotetext{
3The appropriate real rate of interest for purposes of evaluating public investments is a subject of continuing debate. Within the government of British Columbia the recommended rate has been as high as 10 percent (Environment and and Canter for the Economic Council of Canada (Jenkins 1977). The three percent adopted here is the rate of return on private investments estimated by a private management firm (Wood Gundy Ltd. 1977).
}

The range of values in Table 4 is striking. They suggest that, under these assumptions, the cost of the timber produced by rehabilitating backlog NSR land would amount to as little as $\$ 5$ per cubic metre on good sites in the Vancouver Forest Region. At the other extreme the cost would cumulate to more than $\$ 180$ per cubic metre on poor sites in remote parts of the province. Between these extremes, all categories of backlog NSR land can be ranked in terms of the relative cost of the timber that can be produced on them through rehabilitation.

Recognizing the restrictive assumptions on which the calculations are based, these costs can be interpreted as the value that the timber must reach at harvest age to recoup the investment in rehabilitation. During the last six years, stumpage prices (in constant 1983 dollars) have averaged $\$ 6$ per cubic metre on the coast and $\$ 3$ per cubic metre in the interior. ${ }^{4}$ This, (combined with our estimates of costs in Table 4) suggests that rehabilitating some sites can be expected to yield a positive return on the investment while on others it cannot, thus underscoring the importance of identifying priorities.

Several qualifications to these estimates are warranted. First, they are based entirely on costs that provide an adequate basis for economic ranking only if a) the objective is to maximize the volume of timber produced, or b) the objective is to maximize the value of production and the value per cubic metre of timber is the same in all circumstances. However, the stumpage value of timber varies considerably among sites, depending on their accessibility, distance from markets, terrain and so on. Thus, if the timber that can be grown on a particular site is sufficiently more valuable than on another, it may deserve priority even though its production costs are higher.

A ranking of sites that would more accurately reflect their relative economic returns to rehabilitation would be based on comparisons of the expected value of the timber with its cost of production, highest priority being given to those sites that will generate the greatest value per dollar of expenditure. For reasons mentioned earlier we have not attempted, in this preliminary analysis, to predict the future value of timber. However, modelling techniques being developed at the Forest Economics and Policy Analysis Project will enable calculation of indices of the net value of timber according to the characteristics of each site, which could be adapted for purposes of reforestation planning (Morrison et al 1986).

Second, the costs we have calculated in Table 4 are averages for each category of land. There is likely to be very broad variation around these averages because of differences among sites in the features that determine costs. Thus the range of costs among specific sites is likely to be considerably greater than the range in these averages, and the ranking among individual sites will not consistently follow that of the averages for broad categories.

Third, the magnitude of the break-even values is highly sensitive to the rate of interest adopted, but an alternative rate does not alter the ranking of categories of land in terms of their returns to rehabilitation. For example, a one percent increase in the interest rate more than doubles the costs, and widens the spread between sites, but the ranking (which is of primary interest here) does not change.

${ }^{4}$ Calculated from Ministry of Forests Annual Reports, 1980 to 1984, and GNE deflator from Statistics Canada 1984 
Table 4. Estimates of the costs of producing timber through rehabilitation of backlog NSR land, by forest region and site class.

\begin{tabular}{|c|c|c|c|c|c|c|c|}
\hline & \multicolumn{7}{|c|}{ Forest Region } \\
\hline & Cariboo & Kamloops & $\frac{\text { Nelson }}{\text { (dol }}$ & $\begin{array}{l}\text { Prince } \\
\text { George } \\
\text { per cubic }\end{array}$ & $\begin{array}{c}\text { Prince } \\
\text { Rupert } \\
\text { (Interior) } \\
\text { etre) }\end{array}$ & $\begin{array}{l}\text { Prince } \\
\text { Rupert } \\
\text { (Coast) }\end{array}$ & Vancouver \\
\hline \multicolumn{8}{|l|}{$\mathrm{NCBr}:$} \\
\hline good sites & 18.7 & 15.3 & 18.0 & 30.3 & 30.5 & 6.8 & 10.7 \\
\hline medium sites & 60.6 & 49.6 & 58.5 & 55.5 & 55.7 & 18.3 & 28.9 \\
\hline poor sites & 125.6 & 103.0 & 121.3 & 182.9 & 183.8 & 104.0 & 163.9 \\
\hline \multicolumn{8}{|c|}{ Other backlog NSR: } \\
\hline good sites & 18.2 & 18.2 & 17.3 & 24.4 & 25.2 & 5.6 & 4.8 \\
\hline medium sites & 59.0 & 59.1 & 56.0 & 44.6 & 46.0 & 15.1 & 13.0 \\
\hline poor sites & 122.3 & 122.6 & 116.1 & 146.9 & 151.7 & 85.9 & 73.9 \\
\hline
\end{tabular}

Source: Appendix A and B.

Fourth, our silvicultural costs are based on 1983 data. Whether these costs will increase over time in real terms (that is, in excess of the rate of inflation) is questionable; even if they do, increases in productivity in the relatively new silviculture industry may well offset any rise in the real costs of labour and equipment.

Fifth, to the extent that the labour employed for this purpose would otherwise be unemployed, as is the case under some present employment programs, the real costs are exaggerated. And finally, the precision of the estimates depends on the reliability of the data on the areas to be treated, the costs of treating them, and potential harvestable volumes, all of which are based on imperfect information.

\section{The Significance of Economic Priorities}

These findings are sufficient to indicate that the gains in timber supply will be significantly greater if economic considerations are brought to bear on the allocation of the funds available for rehabilitating backlog NSR lands. To illustrate this we have calculated the additional growth that can be obtained by allocating funds to the backlog NSR lands in order of their economic priority rather than by some other method.

One of the goals of the current federal-provincial Forest Resource Development Agreement is to rehabilitate 150,000 hectares of backlog NSR lands over the five years of the agreement. If all of these hectares were selected from good and medium sites in equal proportion to the total areas in these categories in each region, about 25.5 percent of all the backlog NSR lands in these categories would be rehabilitated. This, with the information presented earlier in this paper, enables us to calculate that the cost would total $\$ 142.5$ million. The resulting additional mean annual increment of growth would be 944 thousand cubic metres.

Alternatively, if the same total funds were allocated in accordance with the economic priorities indicated in Table 4, it would be possible to reforest the most cost-effective 152 thousand hectares. The resulting additional growth would be 1206 thousand cubic metres per year. This indicates a potential gain of 262 thousand cubic metres per year, or 28 percent in annual timber growth, as a result of adopting economic priorities rather than indiscriminantly rehabilitating lands in the Ministry's NPB category. Generally, the smaller the budget, the larger will be the percentage gain. And, for reasons noted earlier, more site-specific analysis would undoubtedly demonstrate a much greater potential improvement.

\section{Impacts on Timber Supply}

Under present policies for regulating the timber supply, some benefits of rehabilitating unproductive land are realized immediately in the form of increased allowable annual cut in sustained yield management units (Royal Commission on Forest Resources 1976, Ch. 17). This "allowable cut effect" is complicated, and varies with the forest inventory and other conditions in each unit, but it is roughly indicated by the increase in growth (the mean annual increment over the rotation period) that results from establishing crops where otherwise there would be none.

To illustrate the potential magnitude of this effect, if the entire backlog of NSR lands were reforested immediately, the mean annual increment of growth in all of British Columbia would increase by 6.5 million cubic metres. Or, if only the good and medium sites were reforested, the increase would be 3.7 million cubic metres per year. These volumes are roughly the amount that could be added to the currently committed allowable annual cut of 68 million cubic metres per year.

To put this in the perspective of the province's timber supply problem, it should be noted that some of the Ministry's projections of future timber harvests on regulated Crown lands suggest decreases in the allowable annual cut over the next 50 years of some 7 million cubic metres (Ministry of Forests 1984a). Such declines could probably be eliminated through intensive silvicultural effort and, superficially, it appears that rehabilitation of the backlog of unreforested lands, alone, could make a major dent in the expected decline.

However, these aggregate statistics exaggerate the potential benefits of increased harvests from rehabilitating the backlog NSR lands. The timber supply outlook varies greatly among regions and management units; while some face reductions in harvest rates, others offer scope for increases, and these differences are not all correlated with the occurrence of backlog NSR lands. Obviously, wherever the allowable cut is not already fully committed, or where the committed cut is not fully harvested so that the allowable annual cut is not the limiting factor on harvest rates, any addition to the allowable annual cut resulting from reforesting backlog NSR land is not likely to increase harvests. And even in management units where harvest rates are pressing on the limits of the allowable cut, increases may be constrained by the availability of mature timber. In short, the benefits of increased timber supplies that will result from rehabilitating backlog NSR lands are complicated and can be estimated only with reference to a specific plan for each sustained yield unit involved. 


\section{Other Policy Implications}

The calculations presented in this paper demonstrate that attention to economic considerations in establishing priorities for rehabilitating backlog NSR lands can substantially enhance the benefits derived from the available funds. However, we do not mean to imply that economic returns should be the only criterion in allocating silvicultural expenditures. Forest rehabilitation may enhance, or diminish, values other than timber, such as wildlife, recreation and livestock forage, and these impacts should be included in assessing alternatives. Moreover, broader issues such as the timber supply conditions in particular areas, regional employment problems and environmental objectives, among other things, may be appropriate considerations as well. Nevertheless, when such other considerations are brought to bear on decisions, economic analysis of the kind presented here can serve the valuable purpose of revealing cost, in terms of the foregone economic benefits in forestry, of modifying silvicultural programs to serve other objectives in various degrees and locations. It thus provides a base of reference for identifying appropriate objectives and plans.

Because rehabilitating backlog NSR lands involves expensive treatments, incurred at the beginning of the rotation period, this is likely to be one of the more costly silvicultural means of increasing timber supplies. However, to some extent, it must be regarded as necessary to correct past deficiencies in maintaining the productivity of forest lands. The increased yield of timber that can be generated by restocking the backlog NSR land in British Columbia as a whole is distinctly limited, but the impact on local timber supplies may be highly significant in some cases because of its potential leverage through the allowable cut effect.

Available data have restricted us to average information about each site quality class in each region. Moreover, we have virtually no information about what would happen on backlog lands if they were not rehabilitated; the rate at which they would restock naturally is likely to vary considerably among sites and regions, and this should be recognized in establishing priorities for silvicultural treatment. More exacting analysis would take account of these and other site-specific conditions that influence the costs and benefits of forest rehabilitation and of subsequent stand tending as well. 5 This would undoubtedly demonstrate a wider range of economic opportunities for silvicultural effort, and enable a much more advantageous allocation of funds.

The search for data for this study has revealed certain weaknesses in the resource information available. Our companion study emphasizes the imprecision of inventory data (Pearse, Lang and Todd 1986). Probably the most serious deficiency in biological information relates to the patterns of growth in managed forests. Our understanding of silvicultural needs, about such fundamental issues as where natural regeneration will occur in both current and backlog NSR areas and where planting is necessary, is also an obstacle to management planning. This is paralleled by a lack of any systematic method of evaluating the relative economic advantages of planting, site preparation for natural regeneration, and other silvicultural alternatives.

Indeed, our investigation of the reforestation issues in British Columbia has left us with the impression that the information and data-gathering systems are not well attuned to the major policy questions at stake. The most basic question facing policy-makers is whether we are planting enough trees to meet our objectives; but statistical information does not lend itself to an answer to this question. Nor does it throw much light on whether the seedlings are being planted in the right place, whether they are surviving, whether lands left unplanted will restock naturally, and other questions basic to effective assessment of policies and programs.

Plans and funding for the next five years provide for rehabilitation of about 11.5 percent of the backlog NSR land, or about one quarter of the good and medium sites. Because forest restoration is costly, and the funds are limited, priorities must be carefully established. To do this with reasonable confidence, we need much more attention to evaluation techniques of the kind we have suggested in this paper, and data that is better suited to these purposes.

\section{References}

Canada-British Columbia 1985. Forest Resource Development Agreement (1985-1990). 29 pp

Canadian Institute of Forestry. 1983. A Case for Improved Forest Management in Canada. Brief submitted to the Macdonald Royal Commission, Ottawa. Reprinted in Forestry Chronicle 60: $29-33$

Environment Canada. 1984. The Need for Forest Renewal and Management in British Columbia. Background paper for the Canada-British Columbia Agreement on Forest Renewal and Management. Supply and Services. Ottawa. 47 pp.

Environment and Land Use Committee Secretariat. 1977. Guidelines for Benefit Cost Analysis. Victoria.

Jenkins, G.P. 1977. Capital in Canada: It's Social and Private Performance, 1965-1974. Economic Council of Canada Discussion Paper No. 98

Painter, M.F. and Associates Ltd. 1984. Not Satisfactorily restocked (NSR) Lands in British Columbia - an Analysis of the Current Situation. Prepared for the Association of BC Professional Foresters. Vancouver. $18 \mathrm{pp}$.

Ministry of Forests. 1980. Forest and Range Resource Analysis Technical Report. Queen's Printer. Victoria.

Ministry of Forests. 1984a. Forest and Range Resource Analysis Queen's Printer. Victoria.

Ministry of Forests. 1984b. Five-Year Plan - Steady State Silviculture Branch internal Document. Victoria

Ministry of Forests. 1985. Ministry of Forests Annual Report 1983 84. Queen's Printer. Victoria. 54 pp

Morrison, P.D., R. Gasson, G.A. Armstrong and D.H. Williams. 1986. The Recovery Cost of the Merchantable Timber in Coastal British Columbia. Forest Economics and Policy Analysis Project. Information Report 85-8. UBC. Vancouver $48 \mathrm{pp}$.

Pearse, P.H., A.J. Lang and K. Todd. 1986. The Backlog of Unstocked Forest Land in British Columbia and the Impact of Reforestation Programs. For. Chron. 62: 514-521.

Royal Commission on Forest Resources. 1976. Timber Rights and Forest Policy in British Columbia. (Peter H. Pearse, Commissioner). Queen's Printer. Victoria. Ch. 17

Statistics Canada. 1984. System of National Accounts, Nationa Income and Expenditure Accounts: The Annual Estimates. Catalogue 13-201. Supply and Services, Ottawa.

Wood Gundy Ltd. 1977. Canadian Economy Forecast for April. Toronto. 
APPENDIX A

Table 5. Treatment costs associated with reforesting backlog NSR lands ${ }^{a}$

\begin{tabular}{|c|c|c|c|c|c|c|c|c|c|c|}
\hline \multirow[b]{2}{*}{ Forest Region } & \multicolumn{5}{|c|}{ NCBr } & \multicolumn{5}{|c|}{ Other backlog NSR } \\
\hline & $\begin{array}{c}\text { Site } \\
\text { preparation }\end{array}$ & $\begin{array}{l}\text { Planting } \\
\text { Stock }\end{array}$ & Planting & $\begin{array}{c}\text { Allowance } \\
\text { for } \\
\text { Plantation } \\
\text { Failure }^{b}\end{array}$ & $\begin{array}{l}\text { Total } \\
\text { Cost }\end{array}$ & $\begin{array}{c}\text { Site } \\
\text { Preparation }\end{array}$ & $\begin{array}{l}\text { Planting } \\
\text { Stock }\end{array}$ & Planting & $\begin{array}{c}\text { Allowance } \\
\text { for } \\
\text { Plantation } \\
\text { Failure }^{b}\end{array}$ & $\begin{array}{l}\text { Total } \\
\text { Cost }\end{array}$ \\
\hline \multicolumn{11}{|c|}{ (dollars per hectare) } \\
\hline Cariboo & 309 & 250 & 312 & 70 & 941 & 223 & 250 & 375 & 68 & 916 \\
\hline Kamloops & $218^{\circ}$ & 250 & 246 & 57 & 771 & 307 & 250 & 293 & 68 & 918 \\
\hline Nelson & 292 & 250 & 299 & 67 & 908 & 224 & 250 & 331 & 64 & 869 \\
\hline Prince George & 421 & 250 & 286 & 77 & 1034 & 210 & 250 & 309 & 62 & 831 \\
\hline Prince Rupert & 454 & 250 & 258 & 77 & 1039 & 209 & 250 & 335 & 64 & 858 \\
\hline Vancouver & 989 & 250 & 276 & 121 & 1636 & 124 & 250 & 309 & 55 & 738 \\
\hline
\end{tabular}

${ }^{a}$ Costs are identical on all site classes.

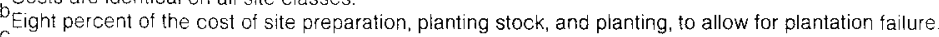

This figure is apparently artificially low because revenues from decadent timber harvested on certain rehabilitated lands were deducted from rehabilitation costs (source: personal communication This figure is apparently artificioly
from Ministry of Forests).

Sources: Ministry of Forests $1984 \mathrm{~b}$ and 1985. The Ministry's reported costs per hectare have been increased by 15 percent to allow for overhead. The cost of planting stock was estimated.

\section{Appendix B}

For the purposes of the calculations in this paper, the forest stands to be established on rehabilitated NSR lands were assumed to be harvestable at the age at which their mean annual increment (m.a.i.) of growth is maximized. Estimates of these rotation ages, by species and site class,

were based on the Ministry of Forests' managed stand yield tables for Douglas-fir, lodgepole pine, and spruce. The species most likely to be planted in each forest region was selected and its rotation age and mean annual increment interpolated for each site category, as shown in Table 6.

Table 6. Rotation ages and growth rates, by forest region and site class.

\begin{tabular}{|c|c|c|c|c|c|c|c|}
\hline \multirow[b]{2}{*}{ Forest Region } & \multirow[b]{2}{*}{$\begin{array}{l}\text { Leading } \\
\text { species } \\
\end{array}$} & \multicolumn{2}{|c|}{ Good Sites } & \multicolumn{2}{|c|}{ Medium Sites } & \multicolumn{2}{|c|}{ Poor Sites } \\
\hline & & $\begin{array}{c}\text { rotation } \\
\text { age } \\
\text { (years) }\end{array}$ & $\frac{\text { m.a.i. }}{\left(\mathrm{m}^{\frac{3}{3} / h a / y r}\right)}$ & $\begin{array}{l}\text { rotation } \\
\text { age } \\
\text { (years) }\end{array}$ & $\left(m^{\frac{m}{3} / h a / y r}\right)$ & $\begin{array}{l}\text { rotation } \\
\text { age } \\
\text { (years) }\end{array}$ & $\frac{\text { m.a.i. }}{\left(m^{\frac{3}{3} / h a / y r}\right)}$ \\
\hline Cariboo & pine & 90 & 8 & 125 & 5 & 135 & 3 \\
\hline Kamloops & pine & 90 & 8 & 125 & 5 & 135 & 3 \\
\hline Nelson & pine & 90 & 8 & 125 & 5 & 135 & 3 \\
\hline Prince George & spruce & 110 & 8 & 125 & 6 & 160 & 4 \\
\hline Prince Rupert (Coast) & fir & 60 & 15 & 90 & 9 & 135 & 4 \\
\hline Prince Rupert (Interior) & spruce & 110 & 8 & 125 & 6 & 160 & 4 \\
\hline Vancouver & fir & 60 & 15 & 90 & 9 & 135 & 4 \\
\hline
\end{tabular}

\section{FORESTRY POSITION}

\section{Macdonald College of McGill University}

The Morgan Arboretum Association and the Department of Renewable Resources, Faculty of Agriculture, McGill University, invite applications for a full-time tenure track position at the rank of assistant or associate professor. The appointee will also be Director-Curator of the Morgan Arboretum. Administrative experience, effective communication skills, and fluency in English and French desirable. A Ph.D. in one of the areas of forest soil science, forest ecology, urban forestry or private forest management is required as well as curatorial ability. Responsibilities include undergraduate teaching and active research associated with the Arboretum. Salary will be based on a floor value of $\$ 31225.00$ and will be commensurate with qualifications and experience. In accordance with Canadian immigraiton requirements, this advertisement is directed to Canadian citizens and permanent residents in the first instance. Send a detailed curriculum vitae and the names of three referees by February 5 , 1987 to:

$$
\text { Dr. R.D. Titman, Chairman }
$$

Department of Renewable Resources

Macdonald College of McGill University 21, 111 Lakeshore Road

Ste-Anne-de-Bellevue, Quebec, Canada. H9X 1Co

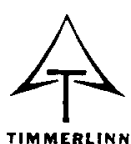

Tel.: (819) 326-3559

TIMMERLINN

\section{TIMMERLINN LIMTrEe}

PROFESSIONAL AND TECHNICAL SERVICES IN FORESTRY AND ENVIRONMENTAL SCIENCES

R.R. No. 2, STE. AGATHE DES MONTS, QUE. J8C $2 Z 8$ 